\title{
Bufalin induces apoptosis in the U-2OS human osteosarcoma cell line via triggering the mitochondrial pathway
}

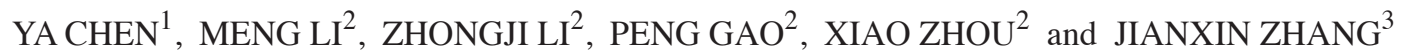 \\ Departments of ${ }^{1}$ Pharmacy and ${ }^{2}$ Orthopaedic Surgery, People's Hospital of Zhangqiu, Shandong 250200; \\ ${ }^{3}$ Spinal Department of Orthopaedic Surgery, Affiliated Hospital of Shandong University of Traditional Chinese Medicine, \\ Jinan, Shandong 250014, P.R. China
}

Received January 6, 2015; Accepted October 6, 2015

DOI: $10.3892 / \mathrm{mmr} .2015 .4583$

\begin{abstract}
Bufalin has been shown to induce apoptosis in osteosarcoma cells; however, the underlying mechanism has not been elucidated. The purpose of the present study was to investigate whether mitochondria-mediated signaling pathways trigger the process of apoptosis in the U-2OS osteosarcoma cell line. Bufalin inhibited the proliferation and induced apoptosis in U-2OS cells in a time- and dose-dependent manner. Bufalin-induced apoptosis was accompanied with a significant reduction of the mitochondrial membrane potential, release of mitochondrial cytochrome $c$ into the cytosol, activation of caspase-3, caspase-9 and poly(adenosine diphosphate ribose) polymerase, as well as downregulation of B-cell lymphoma 2 (Bcl-2)/Bcl-2-associated X protein. Cyclosporin A, a specific inhibitor of the mitochondrial permeability transition pore, attenuated bufalin-induced apoptosis. In conclusion, the present study revealed that bufalin induced apoptosis in the U-2OS human osteosarcoma cell line via triggering of the mitochondrial pathway.
\end{abstract}

\section{Introduction}

Osteosarcoma (OS), characterized by formation of cancerous bone tissue, is the most frequent primary malignant tumor of bone occurring in children and adolescents $(1,2)$. OS is prone to aggressive biological behavior and development of distant metastasis (3-5). The currently used treatment for OS is neo-adjuvant chemotherapy followed by surgical resection, which has improved the five-year survival rate from 20 to $60 \%(6,7)$. However, OS cells frequently display multi-drug resistance to chemotherapeutic drugs, which poses

Correspondence to: Mr. Jianxin Zhang, Spinal Department of Orthopaedic Surgery, Affiliated Hospital of Shandong University of Traditional Chinese Medicine, 16369 Jingshi Road, Jinan, Shandong 250014, P.R. China

E-mail: dr_jianxin@163.com

Key words: bufalin, apoptosis, human osteosarcoma, U-2OS cells, permeability transition pore, mitochondrial membrane potential a considerable limitation to the clinical curative effect and long-term survival (8). Induction of apoptosis in target cells is a key therapeutic strategy for the extermination of cancer cells; therefore, recent studies have focused on the identification of novel drugs with the ability to induce and enhance apoptosis (9-11).

Bufalin, one of the major components of the Chinese medicine Chan'Su, was shown to exhibit marked anti-tumor activity against leukemia and various types of solid tumor, including prostate cancer, lung cancer and hepatoma (12-19). This anti-tumor activity is achieved by inhibition of proliferation and induction of apoptosis $(18,19)$. Bufalin was shown to be potent against human OS tissues and cell lines via inducing apoptosis $(20,21)$; however, the specific underlying mechanism has remained elusive. Mitochondria-mediated signaling pathways have a pivotal role in the process of apoptosis (22-25), and have been identified to be the underlying mechanism of bufalin-induced apoptosis in various types of tumor cell (21). As the specific mechanisms of action of bufalin vary between different tumor types or even between different phenotypes of the same tumor type, the mechanisms of the effects of bufalin on OS cell lines require to be elucidated. The present study observed the effects of bufalin on the proliferation and apoptosis of the U-2OS human OS cell line and investigated the expression of proteins associated with the mitochondrial apoptotic pathway in the process of U-2OS-cell apoptosis induced by bufalin. The apoptosis of U-2OS cells was explored from the perspective of mitochondrial structure and function, including the open of permeability transition pore (PTP) and dissipation of mitochondrial membrane potential (MMP/ $\Delta \Psi \mathrm{m})$.

\section{Materials and methods}

Materials and reagents. Bufalin and cyclosporin A (CsA) were purchased from Sigma-Aldrich (St Louis, MO, USA). The purity of bufalin was $>99 \%$ as confirmed by high-performance liquid chromatograph (Fig. 1). The Annexin V-fluorescein isothiocyanate (FITC) Apoptosis Detection kit and the Hoechst-propidium iodide (PI) staining assay kit were obtained from BD Biosciences (Franklin Lakes, NJ, USA). The mitochondrial membrane potential detection kit (JC-1; cat. no. 30001) was from Invitrogen (Thermo Fisher Scientific, Waltham, MA, USA). Antibodies specific for polyclonal 
rabbit anti-human B-cell lymphoma 2 (Bcl-2; cat. no. 2876; 1:1,000), Bcl-2-associated X protein (Bax; cat. no. 2772; 1:1,000), monoclonal mouse anti-rat caspase-3 (1:500), monoclonal mouse anti-rat caspase-9 (1:500) and anti-human $\beta$-actin (cat. no. 4967; 1:1,000) were purchased from Santa Cruz Biotechnology (Dallas, TX, USA). Antibodies specific for poly adenosine diphosphate ribose polymerase (PARP), cleaved PARP and cytochrome $c$ were supplied by Abcam (Cambridge, UK).

U-2OS cell culture. The U-2OS human OS cell line was provided by the Shanghai Institutes for Biological Sciences, the Chinese Academy of Sciences (Shanghai, China). Cells were cultured in 1\% Dulbecco's modified Eagle's medium (DMEM; Gibco; Thermo Fisher Scientific, Inc.) containing 10\% fetal bovine serum (FBS), 100 units/ml penicillin and $100 \mu \mathrm{g} / \mathrm{ml}$ streptomycin (100 Biotech Co., Ltd., Hangzhou, China), and grown at $37^{\circ} \mathrm{C}$, in a humidified atmosphere containing $5 \%$ $\mathrm{CO}_{2}$. Cells in the logarithmic growth phase were used in all experiments.

Cellproliferation assay. The 3-(4,5-dimethylthiazol-2-yl)-2,5-diphenyltetrazolium bromide) MTT method was used to assess the effects of bufalin on the cell proliferation. U-2OS cells ( $2 \times 10^{3}$ cells/well) in the logarithmic growth phase were seeded in 96 -well plates. Following $24 \mathrm{~h}$ incubation at $37^{\circ} \mathrm{C}$, the cells were treated with various concentrations of bufalin $(10,20$ or $50 \mu \mathrm{g} / \mathrm{l})$ for 6,12 and $24 \mathrm{~h}, 10 \mu \mathrm{l}$ MTT $(5 \mathrm{mg} / \mathrm{ml})$ was added. Following $4 \mathrm{~h}$ of incubation, the culture media was discarded and $100 \mu \mathrm{l}$ dimethylsulfoxide (DMSO) was added to each well to dissolve the formed formazan crystals. The absorbance was measured at $570 \mathrm{nM}$ using an ELISA plate reader (Bio-Rad 550; Bio-Rad Laboratories, Inc., Hercules, CA, USA). Data were collected from three separate experiments and the percentage of bufalin-induced cell growth inhibition was determined by comparison with DMSO-treated control cells.

Apoptosis assay. The apoptotic rate was determined using Hoechst 33258 staining following fluorescence-microscopic evaluation as well as by Annexin V-FITC/PI double labeling and flow cytometric analysis. U-2OS cells $\left(1 \times 10^{5}\right.$ cells/well $)$ were cultured in 12-well flat-bottomed microtiter plates for $24 \mathrm{~h}$ and subsequently incubated with $1 \%$ DMSO (control cells) or $50 \mu \mathrm{g} / 1$ bufalin for $24 \mathrm{~h}$. After fixing in $4 \%$ paraformaldehyde (Bio-Rad Laboratories, Inc.) for $15 \mathrm{~min}$ at room temperature and staining with $10 \mathrm{ng} / \mathrm{ml}$ Hoechst 33258, apoptotic cells were identified by their characteristic nuclear morphology observed under an inverted fluorescence microscope (CK40 F200; Olympus Corporation, Tokyo, Japan). After treatment with various concentrations $(10,20$ or $50 \mu \mathrm{g} / \mathrm{l})$ of bufalin for various durations $(6,12$ or $24 \mathrm{~h}), \mathrm{U}-2 \mathrm{OS}$ cells were harvested, suspended in phosphate-buffered saline (PBS), and stained with Annexin V-FITC and PI according to the manufacturer's instructions of the Apoptosis Detection kit. Flow cytometry (FACSort; BD Biosciences) was used to quantify apoptotic U-2OS cells.

Flow cytometric detection of $\Delta \Psi m . \Delta \Psi \mathrm{m}$ was assessed using 5,5',6,6'-tetrachloro-1,1',3,3'-tetraethylbenzimidazolylcarbocyanine iodide (JC-1). The cells in the logarithmic growth

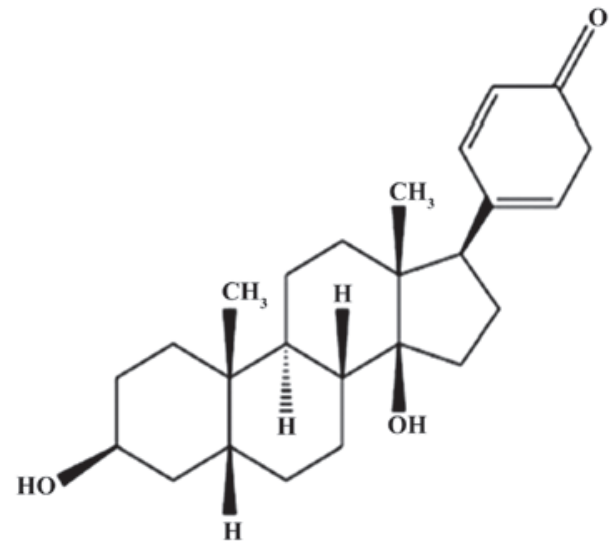

Figure 1. Chemical structure of bufalin.

phase were seeded into 12-well flat-bottomed microtiter plates at a density of $2 \times 10^{5}$ cells. Following incubation for $24 \mathrm{~h}$ to allow for cell adherence, the cells were treated with 10-50 $\mu \mathrm{g} / 1$ bufalin for $24 \mathrm{~h}$ and washed with pre-cooled PBS. The cells were then collected by centrifugation $\left(4^{\circ} \mathrm{C}, 1,000 \times \mathrm{g}, 5 \mathrm{~min}\right)$, washed with PBS and re-suspended in $1 \mathrm{ml}$ PBS. The cells were incubated in $0.5 \mathrm{ml}$ medium containing JC-1 $(1.0 \mu \mathrm{g} / \mathrm{ml})$ for $30 \mathrm{~min}$ at $37^{\circ} \mathrm{C}$ and staining was quantified using flow cytometry. In mitochondria with an intact $\Delta \Psi \mathrm{m}, \mathrm{JC}-1$ is concentrated to form aggregates with red fluorescence, while accumulation of JC-1 in mitochondria with $\Delta \Psi \mathrm{m}$ loss is reduced, resulting in single JC-1 molecules with green fluorescence.

Western blot analysis. For western blot analysis, U-2OS cells were subjected to the abovementioned drug treatments and total protein was then extracted using $1 \%$ Nonidet P-40 (Pierce Biotechnology, Inc., Rockford, IL, USA). Each sample was centrifuged at $15,000 \mathrm{x}$ for $30 \mathrm{~min}$ at $4^{\circ} \mathrm{C}$ and the supernatant was collected. Protein concentration was determined using a bicinchoninic acid assay kit (Beyotime Institute of Biotechnology, Haimen, China). Equal amounts of protein $(30 \mu \mathrm{g})$ were subjected to $12 \%$ sodium dodecyl sulfate-polyacrylamide gel (Invitrogen; Thermo Fisher Scientific, Inc.) electrophoresis and transferred onto a polyvinylidene difluoride membrane (EMD Millipore, Billerica, MA, USA). Levels of cytoplasmic cytochrome c, PARP, cleaved PARP, caspase-3, caspase-9, Bax and Bcl-2 were assessed using western blot analysis. Following blocking in $5 \%$ non-fat dry milk for $1 \mathrm{~h}$, the blots were incubated with the following primary antibodies: Polyclonal rabbit anti-human Bcl-2 (1:1,000; cat. no. 2876); polyclonal rabbit anti-human Bax (1:1,000; cat. no. 2772) antibody; monoclonal mouse anti-rat caspase-3 (1:500; cat. no. 1992), monoclonal mouse anti-rat caspase 9 (1:500, cat. no. 0620) antibody; polyclonal mouse anti-human PARP (1:1,000; cat. no. ab30889); polyclonal mouse anti-human cleaved PARP (1:1,000; cat. no. ab72805); polyclonal rabbit anti-human cytochrome $c$ $\left(1: 1,000\right.$; cat. no. 1116) antibody, for $12 \mathrm{~h}$ at $4^{\circ} \mathrm{C}$ followed by three 5 min washes in Tris-buffered saline with Tween-20. Mouse or rabbit secondary antibody (1:2,000; cat. no. 2357) conjugated with horseradish peroxidase was added to the membrane and incubated for $1 \mathrm{~h}$ at room temperature. Protein bands were visualized on X-ray films (Sigma-Aldrich) using 


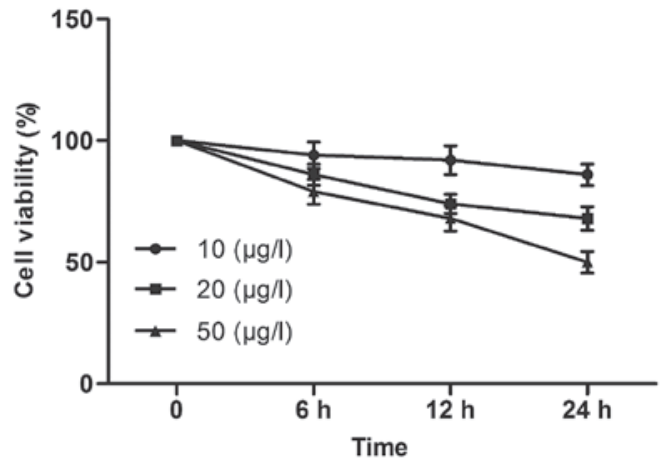

Figure 2. Bufalin inhibits the proliferation of the U-2OS human osteosarcoma cell line. U-2OS cells were treated with 10,20 or $50 \mu \mathrm{g} / 1$ bufalin for 6,12 or $24 \mathrm{~h}$. Bufalin concentration- and time-dependently reduced the viability of U-2OS cells. Values are expressed as the mean \pm standard deviation $(n=3)$.
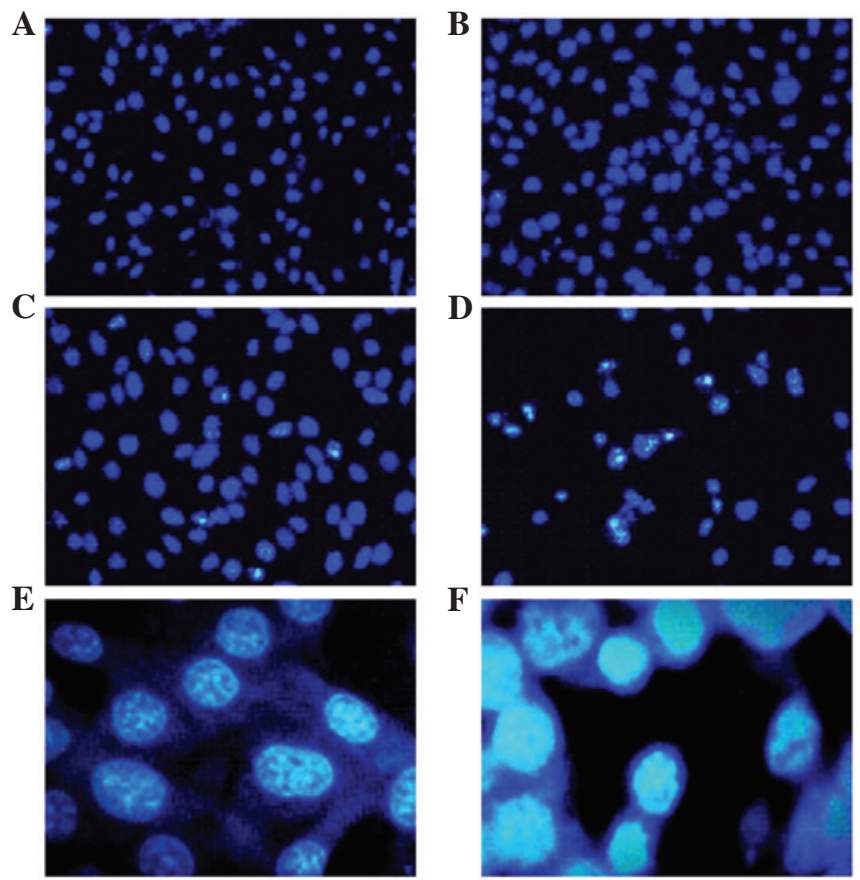

Figure 3. Fluorescence-microscopic assessment of the morphology of apoptosis of U-2OS cells following bufalin treatment with Hoechst 33258 staining. Cells were (A) Untreated or treated with (B) 10, (C) 20 or (D) $50 \mu \mathrm{g} / 1$ bufalin for $48 \mathrm{~h}$ (magnification, x100). Bufalin dose-dependently increased the apoptotic rate of U-2OS cells. Magnified images showing staining of apoptosis-associated chromatin fragments in (E) untreated cells and (F) cells incubated with $50 \mu \mathrm{g} / 1$ bufalin (magnification, $\mathrm{x} 400$ ). Apoptotic cells showed cytoplasmic shrinkage, nuclear condensation, nuclear fragmentation and the formation of apoptotic bodies. Images are representative of four independent experiments.

an enhanced chemiluminescence detection system (Applygen Technologies, Inc., Beijing, China). $\beta$-actin was used as an internal control for relative quantification. Grey value analysis of immunoreactive bands was performed using Quantity One 16.0 software (Bio-Rad Laboratories, Inc., Hercules, CA, USA).

Statistical analysis. Values are expressed as the mean \pm standard deviation of three experiments. Statistical comparisons were performed using one-way analysis of variance. Statistical
$\mathbf{A}$

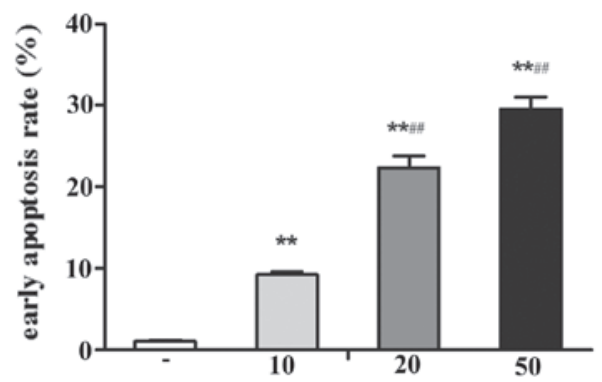

$\mathbf{B}$

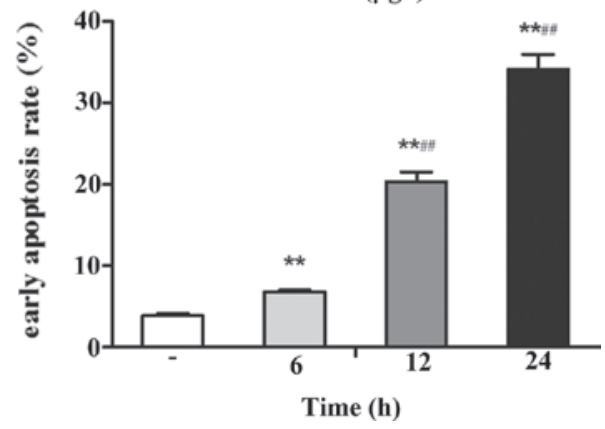

Figure 4. Flow-cytometric analysis of apoptotic rates of U-2OS cells induced by bufalin. (A) U-2OS Cells were incubated with $0,10,20$ or $50 \mu \mathrm{g} / 1$ bufalin for $24 \mathrm{~h}$. (B) Cells were incubated with $50 \mathrm{nmol} / 1$ bufalin for $0,6,12$ or $24 \mathrm{~h}$. Bufalin enhanced the apoptotic rate of U-2OS cells in a dose- and time-dependent manner. Values are expressed as the mean \pm standard deviation $(\mathrm{n}=3) .{ }^{* *} \mathrm{P}<0.01$ vs. control group; ${ }^{\# \#} \mathrm{P}<0.01$ vs. $10 \mu \mathrm{g} / 1$ bufalin group.

analysis was conducted using SPSS 13.0 (SPSS, Inc., Chicago, IL, USA). $\mathrm{P}<0.05$ was considered to indicate a statistically significant difference between bufalin-treated groups and the control group.

\section{Results}

Bufalin inhibits the viability of U-2OS cells. U-2OS cells were exposed to various concentrations of bufalin for 6,12 and $24 \mathrm{~h}$ and subjected to MTT assays (Fig. 2). Bufalin at $10 \mu \mathrm{g} / \mathrm{l}$ produced minor decreases of cell viability with increasing time, while $50 \mu \mathrm{g} / \mathrm{l}$ bufalin induced a marked time-dependent inhibition of U-2OS-cell viability. Following exposure to 10,20 and $50 \mu \mathrm{g} / 1$ bufalin for $24 \mathrm{~h}$, the cell viability was reduced to $86 \pm 4,68 \pm 5$ and $50 \pm 4 \%$, respectively. These results indicated that bufalin induced a marked concentration- and time-dependent inhibition of U-2OS cells.

Bufalin induces apoptosis in U-2OS cells. After $24 \mathrm{~h}$ of incubation with 10, 20 and $50 \mu \mathrm{g} / \mathrm{l}$ bufalin, U-2OS cells were stained with Hoechst 33258 and observed by fluorescence microscopy. With the increasing concentration of bufalin, the number of apoptotic cells increased gradually (Fig. 3A-D). Morphological observation (magnification, $\mathrm{x} 400$ ) revealed that U-2OS control cells exhibited integrated and lightly stained nuclei with uniform chromatin density, while morphological characteristics of apoptosis, including cytoplasmic shrinkage, nuclear condensation, nuclear fragmentation and the formation of apoptotic bodies, were observed in U-2OS cells treated with bufalin (Fig. 3E and F).

Flow-cytometric determination of the apoptotic rate revealed that bufalin induced early apoptosis of U-2OS cells in 

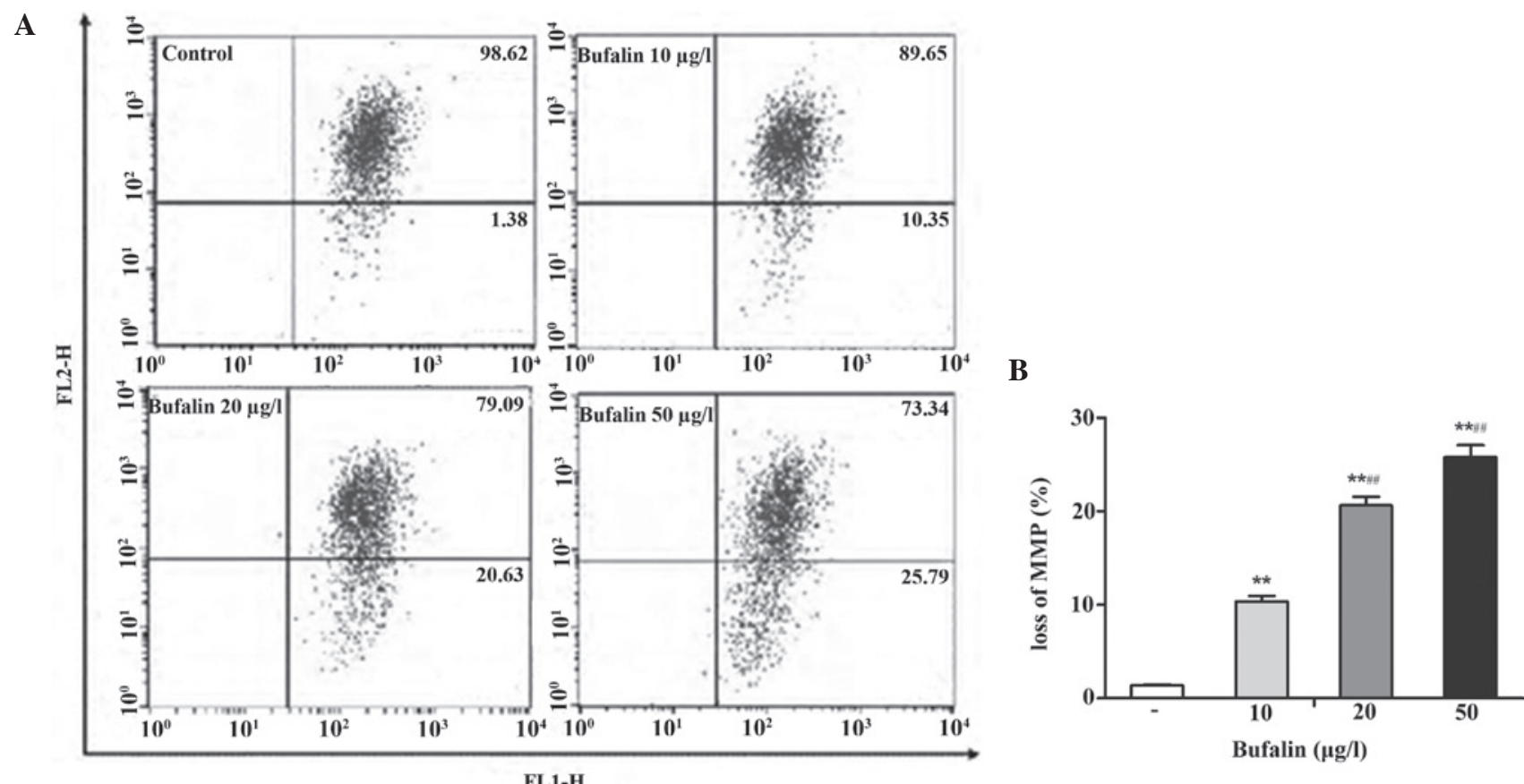

Figure 5. Bufalin induces loss of the $\Delta \Psi \mathrm{m}$. (A) Flow cytometric analysis of JC-1-stained U-2OS cells following treatment with bufalin. Percentages of green red-fluorescent cells (representative of intact and lost $\Delta \Psi \mathrm{m}$, respectively) are stated in the upper and lower right quadrants, respectively. Dot plots representative of three experiments with similar results are shown. (B) Quantification of A showing that bufalin decreased $\Delta \Psi \mathrm{m}$ in a concentration-dependent manner. Values are expressed as the mean \pm standard deviation $(\mathrm{n}=3) .{ }^{* *} \mathrm{P}<0.01 \mathrm{vs}$. control group; ${ }^{\# *} \mathrm{P}<0.01 \mathrm{vs} .10 \mu \mathrm{g} / 1$ bufalin group. $\Delta \Psi \mathrm{m} / \mathrm{MMP}$, mitochondrial transmembrane potential.

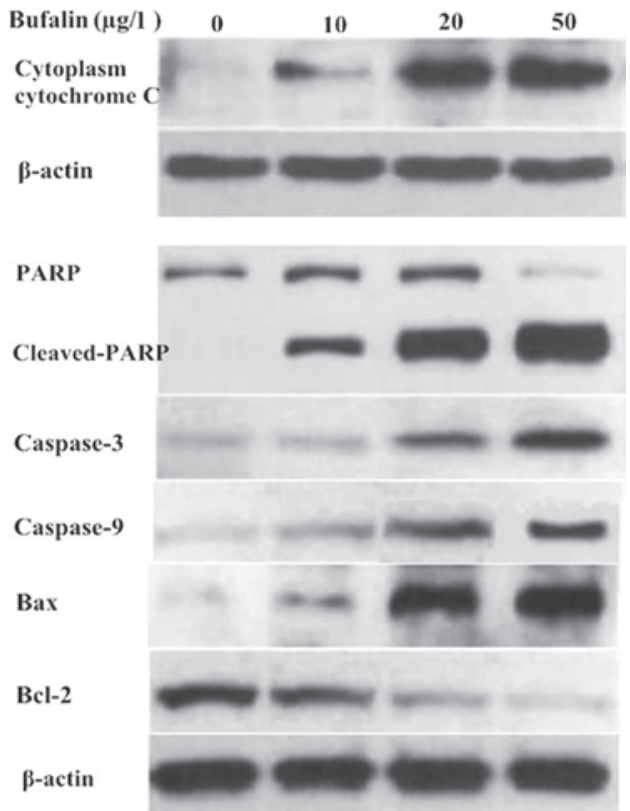

Figure 6. Western blot analysis of U-2OS cells. Following exposure to 10 20 and $50 \mu \mathrm{g} / 1$ bufalin for $24 \mathrm{~h}$, enhanced activities of cytoplasmic cytochrome $c$, cleaved PARP, caspase- 3 and caspase- 9 as well as downregulation of Bcl-2/Bax were detected. Blots representative of three experiments with similar results are shown. PARP, poly(adenosine diphosphate ribose) phosphatase; Bcl-2, B-cell lymphoma 2; Bax, Bcl-2-associated X protein.

a dose- and time-dependent manner. Treatment with 10,20 and $50 \mu \mathrm{g} / \mathrm{l}$ bufalin for $24 \mathrm{~h}$ significantly increased the apoptotic rates to $9.28 \pm 0.31,22.40 \pm 1.38$ and $29.54 \pm 1.55 \%$, respectively $(\mathrm{P}<0.05$ vs. control group; $1.06 \pm 0.11 \%)$ (Fig. $4 \mathrm{~A})$. In addition, incubation with $50 \mu \mathrm{g} / \mathrm{l}$ bufalin for 6,12 and $24 \mathrm{~h}$, increased the apoptotic rate to $6.83 \pm 0.17,20.33 \pm 1.19$ and $34.17 \pm 1.82 \%$ ( $\mathrm{P}<0.05$ vs. control group; $3.86 \pm 0.33 \%$ ) (Fig. 4B).

Bufalin decreases $\Delta \Psi m$. Since mitochondria have an essential role in the apoptotic process, the present study evaluated whether bufalin triggered mitochondrial events of apoptosis. The loss of $\Delta \Psi \mathrm{m}$ is an irreversible key event during early apoptosis. In order to explore the effects of bufalin on the $\Delta \Psi \mathrm{m}$, JC-1 staining followed by flow-cytometric analysis was performed. As shown in Fig. 5, the red fluorescence (upper right quadrant) was gradually reduced, while the green fluorescence (lower right quadrant) was enhanced by increasing doses of bufalin. This result demonstrated that bufalin promoted the release of JC-1 from the mitochondrial matrix into the cytoplasm, leading to its disaggregation into green-fluorescent JC-1 monomers, which are a marker of mitochondrial membrane depolarization and the loss of $\Delta \Psi \mathrm{m}$. These results indicated that bufalin decreased the $\Delta \Psi \mathrm{m}$ by enhancing the permeability of the mitochondrial membrane to initiate apoptosis.

Bufalin affects the expression of proteins associated with mitochondrial apoptosis. To determine the underlying mechanisms of bufalin-induced U-2OS-cell apoptosis, the expression of apoptosis-associated proteins was evaluated by western blot analysis. With the increasing concentration of bufalin (10, 20 and $50 \mu \mathrm{g} / \mathrm{l})$, the expression of cytoplasmic cytochrome $c$, cleaved PARP, caspase-3, caspase-9 and Bax in the cytosolic fraction of U-2OS cells was upregulated compared with that in the control group. By contrast, Bcl-2 and PARP were downregulated (Fig. 6). These results indicated that OS-cell apoptosis induced by bufalin is mediated via the mitochondrial apoptotic signaling pathway. 

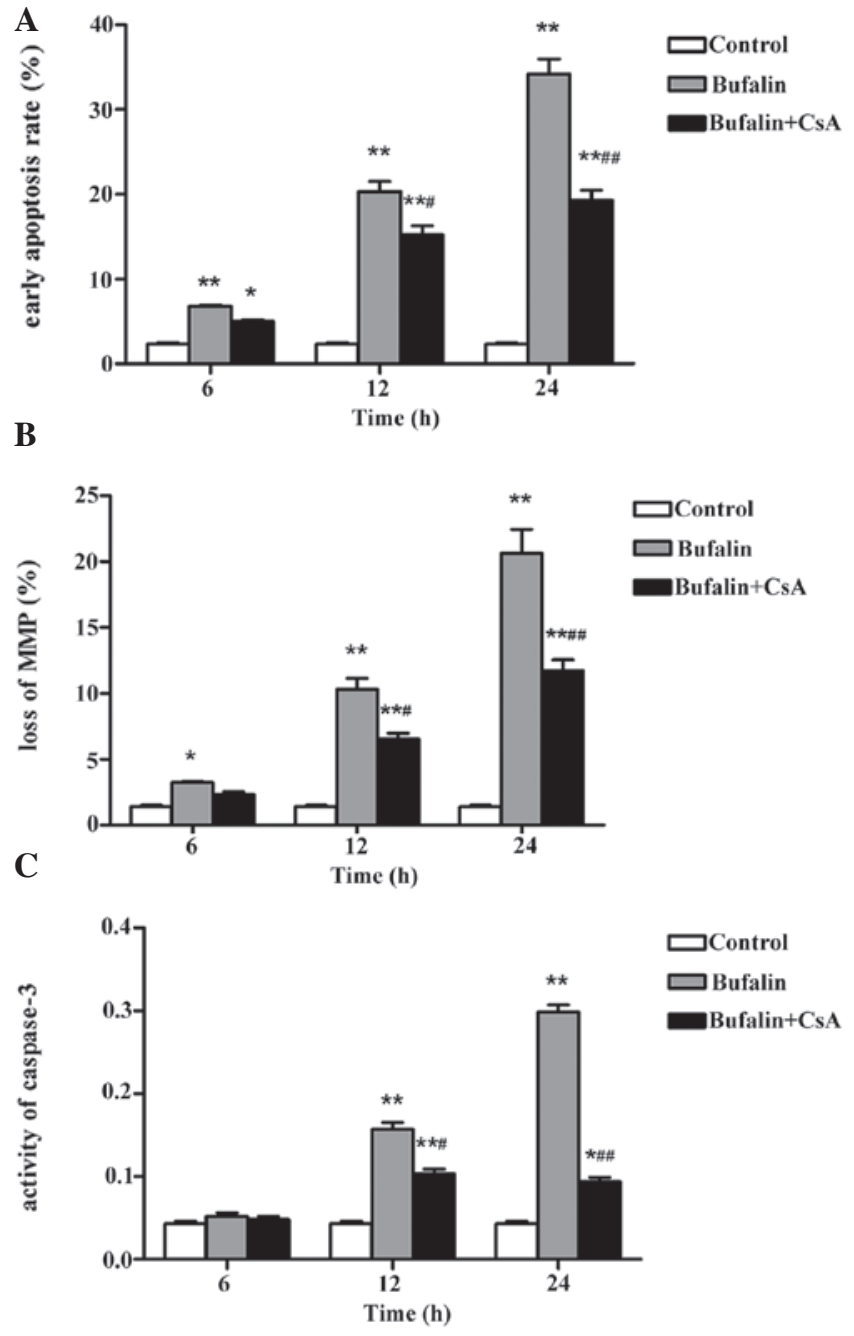

Figure 7. Effects of CsA, a specific inhibitor of the mitochonodrial membrane transition pore, on the apoptotic effects of bufalin on U-2OS cells. (A) Pretreatment with CsA significantly decreased the early apoptotic rate of U-2OS cells treated with bufalin in a time-dependent manner. (B) The loss of $\Delta \Psi \mathrm{m}$ following bufalin exposure was obviously decreased by pre-treatment with CsA. (C) Pre-treatment with CsA significantly decreased the activity of caspase-3 induced by bufalin. Values are expressed as the mean \pm standard error ( $\mathrm{n}=3) .{ }^{*} \mathrm{P}<0.05,{ }^{\text {,**}} \mathrm{P}<0.01$ vs. control group; ${ }^{~} \mathrm{P}<0.05,{ }^{\# \#} \mathrm{P}<0.01$ vs. bufalin group. CSA, cyclosporin A; $\triangle \Psi \mathrm{m} / \mathrm{MMP}$, mitochondrial transmembrane potential.

CsA reduces bufalin-induced apoptosis of U-2OScells. To further assess the effects of mitochondrial transmembrane transport in bufalin-induced apoptosis, U-2OS cells were pre-incubated with CsA, a specific blocker of the PTP. As shown in Fig. 7A, pre-treatment with $2 \mu \mathrm{mol} / 1 \mathrm{CsA}$ for $30 \mathrm{~min}$ significantly decreased the bufalin-induced early apoptotic rate in a time-dependent manner at 12 and $24 \mathrm{~h}(\mathrm{P}<0.05$ and $\mathrm{P}<0.01$, respectively). In addition, CsA pre-treatment significantly reduced the bufalin-induced loss of $\Delta \Psi \mathrm{m}$ in a time-dependent manner at 12 and $24 \mathrm{~h}(\mathrm{P}<0.05$ and $\mathrm{P}<0.01$, respectively) (Fig. 7B). As caspase- 3 is a key mediator and executioner of apoptosis, caspase- 3 activity is regarded to be an index of apoptosis. While the levels of cleaved caspase were significantly increased following incubation with $50 \mu \mathrm{g} / \mathrm{l}$ bufalin for 12 and $24 \mathrm{~h}(\mathrm{P}<0.01)$, pre-incubation with $2 \mu \mathrm{mol} / \mathrm{l}$ CsA for 30 min significantly attenuated caspase-3 activation $(\mathrm{P}<0.05$ and $\mathrm{P}<0.01$, respectively) (Fig. 7C). All of these results indicated that CsA partly inhibited bufalin-induced apoptosis of U-2OS cells.

\section{Discussion}

Bufalin is a biologically active component of the Traditional Chinese Medicine Chan'Su, which has the potential to induce differentiation and apoptosis in a wide spectrum of tumor cells $(26,27)$. Numerous studies have investigated the potential molecular mechanism of the anti-tumor activity of bufalin, indicating that the mitochondria-mediated signaling pathway has a pivotal role in the process of apoptosis induced by bufalin. In the ASTC-a-1 human lung adenocarcinoma cell line, bufalin was shown to induce the translocation of Bax from the cytosol to the mitochondria to activate caspase-3 (28). Masuda et al (29) demonstrated the apoptosis of HL-60 human leukemia cells by altering the expression of apoptosis-associated genes. In androgen-dependent and -independent human prostate cancer, bufalin and cinobufagin were shown to suppress cell proliferation and cause apoptosis via sequence of apoptotic effectors, including Bax, cytochrome $c$ and caspases, all of which are implicated in mitochondria-mediated signaling pathways, which was therefore the predominant apoptotic mechanism induced by bufalin (30). However, the specific mechanism was shown to vary between different tumor types and even within different phenotypes of the same tumor type; therefore, it was required to determine the molecular mechanism of action of bufalin in human OS cells.

In the process of apoptosis triggered by the mitochondria-mediated signaling pathway, the opening of the PTP and subsequent perforation of the mitochondrial membrane decreases the $\Delta \Psi \mathrm{m}$ and leads to the release of cytochrome $c$ into the cytoplasm, were it activates caspases, which amplify the apoptotic signal and disassemble the cytoskeleton (31). The present study revealed that bufalin reduced the viability and induced apoptosis in the U-2OS human OS cell line in a time- and dose-dependent manner. Following $24 \mathrm{~h}$ of incubation, bufalin reduced the $\Delta \Psi \mathrm{m}$ of U-2OS cells in a concentration-dependent manner. In addition, western blot analysis revealed that cytochrome $c$ was released from the mitochondria into the cytoplasm. Furthermore, bufalin dose-dependently increased the levels of active caspase-3 and -9 with resulting decreases in their substrate PARP and increases in the product, cleaved PARP.

The Bcl-2 family of proteins comprise important regulatory factors of cell apoptosis, which include anti-apoptotic proteins, including $\mathrm{Bcl}-2$ and $\mathrm{Bcl}$ extra large protein, as well as pro-apoptotic proteins, including Bax and Bcl-2-associated death promoter, with their main site of action being the mitochondrial outer membrane (32). Bax translocates from the cytosol to the mitochondria where it oligomerizes and permeabilizes the mitochondrial outer membrane to promote apoptosis, and constantly retro-translocates to the cytosol depended on pro-survival Bcl-2 family proteins (33). Upon stimulation by apoptotic signaling in the cell, the $\mathrm{Bax} / \mathrm{Bcl}-2$ ratio is enhanced and the Bax-mediated increases in the permeability of the mitochondrial outer membrane results in the release of the pro-apoptotic proteins from the mitochondria, which activates caspase family members and triggers apoptosis. In the present study, bufalin treatment enhanced the expression of Bax and downregulated the expression of Bcl-2 U-2OS cells, which indicated that the apoptosis of human OS cells induced by bufalin is mediated via the mitochondrial apoptotic signaling pathway. 
The opening of the PTP and the loss of $\Delta \Psi \mathrm{m}$ are considered to be early events in the apoptotic cascade. CsA, a commonly used specific PTP blocker, effectively suppresses apoptosis. Its mechanism of action comprises the inhibition of the combination of mitochondrial matrix protein cyclophilin $\mathrm{D}$ and the multiprotein complex of the PTP, which effects the closing of the PTP. Interruption of the PTP by CsA is a method for studying the involvement of the PTP in metabolic processes (34). Based on this principle, the present study used CsA to explore the role of the PTP in bufalin-induced apoptosis in U2-OS cells. Pre-treatment of the cells with CsA, partly inhibited the apoptotic effects of bufalin, as indicated by attenuation of the early apoptotic rate, loss of $\Delta \Psi \mathrm{m}$ and caspase-3 activity. As CsA, which targets cyclophilin D, reduced bufalin-induced apoptosis, bufalin may indirectly exert its effects via cyclophilin D.

In conclusion, bufalin inhibited the viability and induced apoptosis in U-2OS cells in a time- and dose-dependent manner. Bufalin-induced apoptosis was accompanied by a significant reduction of $\Delta \Psi \mathrm{m}$, the release of mitochondrial cytochrome $c$ into the cytosol, activation of caspase-3 and caspase-9, activating cleavage of PARP and a decrease of the Bcl-2/Bax ratio. CsA, an inhibitor of the PTP, attenuated the apoptosis induced by bufalin. Therefore, bufalin induces apoptosis in the U-2OS human OS cell line via triggering of the mitochondrial pathway.

\section{References}

1. Mirabello L, Troisi RJ and Savage SA: Osteosarcoma incidence and survival rates from 1973 to 2004: Data from the surveillance, epidemiology and end results program. Cancer 115: 1531-1543, 2009.

2. Ottaviani $\mathrm{G}$ and Jaffe $\mathrm{N}$ : The epidemiology of osteosarcoma. Cancer Treat Res 152: 3-13, 2009.

3. Fernandez-Pineda I, Bahrami A, Green JF, McGregor LM, Davidoff AM and Sandoval JA: Isolated subcutaneous metastasis of osteosarcoma 5 years after initial diagnosis. J Pediatr Surg 46: 2029-2031, 2011

4. Sampo MM, Tarkkanen M, Kivioja AH, Taskinen MH, Sankila R and Böhling TO: Osteosarcoma in Finland from 1971 through 1990: A nationwide study of epidemiology and outcome. Acta Orthop 79: 861-866, 2008

5. Osborne TS and Khanna C: A review of the association between osteosarcoma metastasis and protein translation. J Comp Pathol 146: 132-142, 2012.

6. Bernthal NM, Federman N, Eilber FR, Nelson SD, Eckardt JJ, Eilber FC and Tap WD: Long-term results ( $>25$ years) of a randomized, prospective clinical trial evaluating chemotherapy in patients with high-grade, operable osteosarcoma. Cancer 118: 5888-5893, 2012.

7. Jaffe N, Carrasco H, Raymond K, Ayala A and Eftekhari F: Can cure in patients with osteosarcoma be achieved exclusively with chemotherapy and abrogation of surgery? Cancer 95: 2202-2210, 2002.

8. Serra M, Scotlandi K, Manara MC, Maurici D, Lollini PL, De Giovanni C, Toffoli G and Baldini N: Establishment and characterization of multidrug-resistant human osteosarcoma cell lines. Anticancer Res 13: 323-329, 1993

9. Li J, Zhang F and Wang S: A polysaccharide from pomegranate peels induces the apoptosis of human osteosarcoma cells via the mitochondrial apoptotic pathway. Tumour Biol 35: 7475-7482, 2014.

10. Xie X, Yin J, Jia Q, Wang J, Zou C, Brewer KJ, Colombo C, Wang Y, Huang G and Shen J: Quercetin induces apoptosis in the methotrexate-resistant osteosarcoma cell line U2-OS/MTX300 via mitochondrial dysfunction and dephosphorylation of Akt. Oncol Rep 26: 687-693, 2011

11. Zhao XH, Xu ZR, Zhang Q and Yang YM: Simvastatin protects human osteosarcoma cells from oxidative stress-induced apoptosis through mitochondrial-mediated signaling. Mol Med Rep 5: 483-488, 2012.

12. Cao Hong, Shibayama-Imazu T, Masuda Y, Shinki T, Nakajo S and Nakaya K: Involvement of Tiam1 in apoptosis induced by bufalin in HeLa cells. Anticancer Res 27: 245-249, 2007.
13. Dong Y, Yin S, Li J, Jiang C, Ye M and Hu H: Bufadienolide compounds sensitize human breast cancer cells to TRAIL-induced apoptosis via inhibition of STAT3/Mcl-1 pathway. Apoptosis 16: 394-403, 2011.

14. Gu W, Liu L, Fang FF, Huang F, Cheng BB and Li B: Reversal effect of bufalin on multidrug resistance in human hepatocellular carcinoma BEL-7402/5-FU cells. Oncol Rep 31: 216-222, 2014.

15. Hu F, Han J, Zhai B, Ming X, Zhuang L, Liu Y, Pan S and Liu T: Blocking autophagy enhances the apoptosis effect of bufalin on human hepatocellular carcinoma cells through endoplasmic reticulum stress and JNK activation. Apoptosis 19: 210-223, 2014.

16. Kurosawa M, Tani Y, Nishimura S, Numazawa S and Yoshida T: Distinct PKC isozymes regulate bufalin-induced differentiation and apoptosis in human monocytic cells. Am J Physiol Cell Physiol 280: C459-464, 2001.

17. Yin PH, Liu X, Qiu YY, Cai JF, Qin JM, Zhu HR and Li Q: Anti-tumor activity and apoptosis-regulation mechanisms of bufalin in various cancers: New hope for cancer patients. Asian Pac J Cancer Prev 13: 5339-5343, 2012

18. Zhu Z, Li E, Liu Y, Gao Y, Sun H, Wang Y, Wang Z, Liu X, Wang Q and Liu Y: Bufalin induces the apoptosis of acute promyelocytic leukemia cells via the downregulation of survivin expression. Acta Haematol 128: 144-150, 2012.

19. Zhu Z, Sun H, Ma G, Wang Z,Li E, Liu Y and Liu Y: Bufalin induces lung cancer cell apoptosis via the inhibition of pi3k/akt pathway. Int $\mathrm{J}$ Mol Sci 13: 2025-2035, 2012

20. Chang Y,Zhao Y,Zhan H, Wei X, Liu T and Zheng B: Bufalin inhibits the differentiation and proliferation of human osteosarcoma cell line hMG63-derived cancer stem cells. Tumour Biol 35: 1075-1082, 2014.

21. Wang D and Bi Z: Bufalin inhibited the growth of human osteosarcoma MG-63 cells via down-regulation of Bcl-2/Bax and triggering of the mitochondrial pathway. Tumour Biol 35: 4885-4890, 2014.

22. Arora $\mathrm{S}$ and Tandon S: Achyranthes aspera root extracts induce human colon cancer cell (colo-205) death by triggering the mitochondrial apoptosis pathway and s phase cell cycle arrest. Scientific World Journal 2014: 129697, 2014.

23. Kluck RM, Bossy-Wetzel E, Green DR and Newmeyer DD: The release of cytochrome $\mathrm{c}$ from mitochondria: A primary site for Bcl-2 regulation of apoptosis. Science 275: 1132-1136, 1997.

24. Li G, Miskimen KL, Wang Z, Xie XY, Brenzovich J, Ryan JJ, Tse W, Moriggl R and Bunting KD: STAT5 requires the N-domain for suppression of miR15/16, induction of bcl-2 and survival signaling in myeloproliferative disease. Blood 115: 1416-1424, 2010.

25. Shimizu S, Takehara T, Hikita H, Kodama T, Miyagi T, Hosui A, Tatsumi T, Ishida H, Noda $\mathrm{T}$ and Nagano $\mathrm{H}$ : The let-7 family of microRNAs inhibits Bcl-xL expression and potentiates sorafenib-induced apoptosis in human hepatocellular carcinoma. J Hepatol 52: 698-704, 2010.

26. Zhang LS, Nakaya K, Yoshida T and Kuroiwa Y: Bufalin as a potent inducer of differentiation of human myeloid leukemia cells. Biochemical and biophysical research communications 178: 686-693, 1991.

27. Krenn L and Kopp B: Bufadienolides from animal and plant sources. Phytochemistry 48: 1-29, 1998.

28. Sun L, Chen T, Wang X, Chen Y and Wei X: Bufalin induces reactive oxygen species dependent bax translocation and apoptosis in astc-a-1 cells. Evid Based Complement Alternat Med 2011: 249090, 2011

29. Masuda Y, Kawazoe N, Nakajo S, Yoshida T, Kuroiwa Y and Nakaya K: Bufalin induces apoptosis and influences the expression of apoptosis-related genes in human leukemia cells. Leuk Res 19: 549-556, 1995.

30. Yu CH, Kan SF, Pu HF, Jea Chien E and Wang PS: Apoptotic signaling in bufalin- and cinobufagin-treated androgen-dependent and -independent human prostate cancer cells. Cancer Sci 99: 2467-2476, 2008.

31. Naranmandura $H$, Chen $X$, Tanaka $M$, Wang WW, Rehman K, Xu S, Chen Z, Chen SQ and Suzuki N: Release of apoptotic cytochrome $\mathrm{C}$ from mitochondria by dimethylarsinous acid occurs through interaction with voltage-dependent anion channel in vitro. Toxicol Sci 128: 137-146, 2012.

32. Ola MS, Nawaz M and Ahsan H: Role of Bcl-2 family proteins and caspases in the regulation of apoptosis. Mol Cell Biochem 351: 41-58, 2011.

33. Edlich F, Banerjee S, Suzuki M, Cleland MM, Arnoult D, Wang C, Neutzner A, Tjandra N and Youle RJ: Bcl-x(L) retrotranslocates Bax from the mitochondria into the cytosol. Cell 145: 104-116, 2011.

34. Andre N, Roquelaure B and Conrath J: Molecular effects of cyclosporine and oncogenesis: a new model. Medical hypotheses 63: 647-652, 2004. 